\title{
Inhalt des vierundsechzigsten (achtzehnten) Bandes *).
}

Marginalien. Von Th. Zielinski . . . . . . . . . 1 Aus antiken Schulbüchern. Von 0 . Crusius . . . 142

Zum Margites. Von O. Immisch . . . . . . . . . 633

Die Chorreden in den homerischen Epen. Von C. Hentze 254

Zu Xenophanes. Von Karl Praechter . . . . . . . . 308

'Euripides an die Nacht' Ar. Ran. $1331 \mathrm{ff}$. Von O. Schroeder . 147

Ein Satz aus der Phrygerarie Eur. Or. 1395-1424. Von O. Schroeder 473

Theocritea. Von Carl Wendel . . . . . . . . 269

Nachlese zu den Fragmenten des Astrologen Anubion.

Von Arthur Ludwich . . . . . . . . . . 280

Untersuchungen zur Geschichte des griechischen Briefes.

Von G. A. Gerhard . . . . . . . . . . 27

Heraklit und die Orphiker. Von W. Nestle . . . . 367

Beiträge zur Textgeschichte der Moralia Plutarchs. Von

Hans Wegehaupt . . . . . . . . . . . . 391

Kritisch-exegetisches zu spätantiken Philosophen. Von

Karl Praechter . . . . . . . . . . . . 385



Schriftstellern. Von Fr. Zucker . . . . . . 465

Verkannte Bibelzitate in syrischen und mesopotamischen Inschriften. Von A. Deissmann . . . . . . . . 475

$\left.{ }^{*}\right)$ Die Titel der Miscellen und Lückenbüßer sind mit kleiner Schrift gedruckt. 
Beiträge zur Erklärung und Uebersetzung römischer Komiker.

Von A. Funck . . . . . . . . . . . 158. 314

Die Planeten bei Manilius. Von Th. Breiter . . . . . . 154

Niobe bei Ovid. Von O. Altenburg . . . . . . . 284

Ad siluas Statianas Siluula. Scr. Joh. P. Postgate. . 116

Eine neue Properzhandschrift. Von Paul Köhler . . 414

Chronologische Fragen zu Livius XXI. Von Franz Luterbacher . . . . . . . . . . . . . . 137

Zu Ammianus Marcellinus, Seneca de providentia und Plinius'

Panegyricus. Von Th. Stangl . . . . . . . . 310

De citationibus apud Nonium Marcellum. Von W. M.

Lindsay . . . . . . . . . . . . . . . 438

Zu Iulius Exsuperantius. Von A. E. Schöne . . . . . . 478

Zur lateinischen Scholienlitteratur. Von M. Manitius . 567

Beiträge zur Topographie von Alt-Athen. Von Engelbert Drerup . . . . . . . . . . . . . 66

Formalien der Dekrete Athens. Von A, Mommsen . 506

Cn. Lentulus und P. Dolabella. Von W. v. Voigt . . 341

Metellus Caecatus. Von O. Leuze . . . . . . . 95

Das Geiselwesen bei den Römern. Von A. Matthaei . 224

Die Domänenpolizei in dem römischen Kaiserreiche.

Von M. Rostowzew . . . . . . . . . . . 297

Militaria aus Ammianus Marcellinus. Von Albert Müller 573

Metrische Rücksichten in der Auswahl der Verbalformen bei Homer. Von P. Thouvenin . . . . . . . 321

De attributo titulorum saec. V. Atticorum observationes quaedam. Scr. R. Müller . . . . . . . . 554

Die griechischen Personennamen auf -ov und ihre Entsprechungen im Latein. Von A. Zimmermann. . 
Hectora Hectorem. Zu Cic. Tusc. I. 44. 105. Von T. W. Dougan

Asklepiadeen und Dochmien. Von Otto Schroeder . . 493

Zur Io-Sage. Von Ludwig Deubner . . . . . . 481

Zur Bedeutung des Ammon-Orakels. Von E. Bickel . . . . 149

IUNO. Beiträge zum Verständnis der ältesten und wichtigsten Thatsachen ihres Kultes. Von Walter Otto . . . . . . . . . . . . . . . . 161

'Opsix $\alpha \lambda$ xos und фsuż́pyopos in chemischer Beleuchtung. Von

Paul Diergart . . . . . . . . . . . . . 150

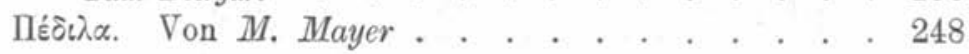

